\title{
Renal Complications and Duration of Diabetes: An International Comparison in Persons with Type 1 Diabetes
}

\author{
Mary Dena $\cdot$ Ann-Marie Svensson · Katarina Eeg Olofsson · \\ Laura Young - Anders Carlson - Kellee Miller · Julia Grimsmann • \\ Reinhard Welp · Julia K. Mader · David M. Maahs · Reinhard W. Holl • \\ Marcus Lind
}

Received: August 27, 2021 / Accepted: September 29, 2021 / Published online: October 25, 2021

(C) The Author(s) 2021

\section{ABSTRACT}

Introduction: Renal complications are both a marker of previous suboptimal glycaemic control and a major risk factor for cardiovascular disease in persons with type 1 diabetes (T1D). The aim of the study was to evaluate the prevalence of renal complications in persons with T1D in four geographical regions.

Methods: Nationwide registry data from Austria/Germany, Sweden and the US were used to estimate the prevalence of renal complications from January 2016 until September 2018.

M. Dena $\cdot$ M. Lind $(\varangle)$

Department of Medicine, NU Hospital Group, Uddevalla, Trollhättan, Sweden

e-mail: marcus.lind@gu.se

M. Dena - A.-M. Svensson - K. E. Olofsson - M. Lind Department of Molecular and Clinical Medicine, Institute of Medicine, University of Gothenburg, Gothenburg, Sweden

L. Young

Diabetes and Endocrinology Clinic at

Meadowmont, UNC Hospitals, Chapel Hill, NC, USA

A. Carlson

International Diabetes Center, Minneapolis, MN, USA

K. Miller

Jaeb Center for Health Research, Tampa, FL, USA
Chronic kidney disease (CKD) and albuminuria in the study population and each registry were analysed by diabetes duration. Risk factors for renal complications were described by registry. Results: In the total cohort of 78.926 adults with T1D, mean age was $44.4 \pm 18.43$ years and mean diabetes duration was $21.6 \pm 22$ years. Mean estimated glomerular filtration rate (eGFR) was $94.0 \pm 31.45 \mathrm{ml} / \mathrm{min}, 13.0 \%$ had microalbuminuria and $3.9 \%$ had macroalbuminuria. Mean age, diabetes duration, use of insulin pumps and continuous glucose monitoring, as well as presence of albuminuria, varied between registries. Albuminuria was present in approximately $10 \%$ of persons with diabetes

J. Grimsmann · R. W. Holl

Institute for Epidemiology and Medical Biometry,

ZIBMT, Ulm University, Ulm, Germany

J. Grimsmann · R. W. Holl

German Centre for Diabetes Research (DZD),

Neuherberg, Munich, Germany

R. Welp

University Duisburg-Essen, Bochum, Germany

J. K. Mader

Department of Internal Medicine, Division of Endocrinology and Diabetology, Medical University of Graz, Graz, Austria

D. M. Maahs

Pediatric Endocrinology, Stanford University, Stanford, CA, USA 
duration $<20$ years and impaired renal function (eGFR $<60 \mathrm{ml} / \mathrm{min}$ ) was present in $17 \%$. In persons with diabetes duration $>40$ years, approximately one-third had albuminuria and $25 \%$ had impaired renal function.

Conclusions: This analysis used three nationwide registries of persons with T1D. Despite recent use of more effective diabetes therapies, a substantial proportion of persons with T1D have renal complications at $<20$ years after diagnosis. Efficient glucose-lowering and renalprotective strategies are needed in persons with T1D.

Keywords: Renal complications; Nephropathy; Type 1 diabetes; Microalbuminuria; Macroalbuminuria; Chronic kidney disease

\section{Key Summary Points}

\section{Why carry out this study?}

Renal complications are both a marker of historical poor glycaemic control and future risk of cardiovascular disease and mortality

The degree of renal complications in the overall type 1 diabetes population and in those with various diabetes durations indicates effects of existing diabetes therapies and future treatment needs

\section{What was the hypothesis of the study?}

We hypothesized that renal complications have decreased compaired to earlier performed evaluations because of more modern therapies and especially in those with diagnoses in the last 1-2 decades receiving more modern therapies

\section{What was learned from the study?}

A substantial proportion of patients with diagnoses in the last 1-2 decades (10\%) had already developed renal complications indicating the need for more efficient diabetes therapies

\section{INTRODUCTION}

Diabetic kidney disease (DKD) is a common microvascular complication that usually develops several years after onset of T1D but may be already present when type 2 diabetes (T2D) is diagnosed [1]. Whether caused by T1D or T2D, DKD is the leading cause of chronic kidney disease, including stages requiring renal replacement therapy. Glomerular hypertrophy, glomerulosclerosis, tubulointerstitial inflammation and fibrosis associated with metabolic changes are the main pathological transformation in the natural history of the disease. Clinically, these findings are associated with progressive albuminuria, declining estimated glomerular filtration rate (eGFR) and end-stage renal disease (ESRD) [1].

Renal complications in persons with T1D are generally both a marker for past or current inadequate glycaemic control [2-4] and a major risk factor for future cardiovascular disease and mortality [5-8]. Consequently, the prevalence of renal complications indicates the extent to which the person has been exposed to substantial hyperglycaemia. Moreover, the prevalence of renal complications indicates to what extent persons with T1D will have increased future cardiovascular risk [9]. Since the early 1990s intensive treatment of diabetes, including use of multiple daily insulin injections (MDI) and blood pressure control [2] and later insulin pumps and modern insulin analogues, significantly improved the treatment of diabetes [10]. These treatment shifts may have significantly influenced complications among persons with T1D since microvascular complication rates are strongly related to the total historical glycaemic exposure [3, 11], glucose variability and glycosylated haemoglobin (HbA1c) variability [12]. Continuous glucose monitoring (CGM) has also become more common over the last decade, which is known to further improve glycaemic control compared with capillary finger-stick testing $[13,14]$.

Population-based studies and registries, especially in Europe, initially focused on risk factors and treatments [15], but recent evaluations from diverse regions are lacking. The aim 
of the current study was to evaluate the prevalence of renal complications in persons with T1D from diabetes registries in different geographical regions. We used data on renal complication in persons with T1D from three registries (Austria/Germany, Sweden and the US).

\section{METHODS}

We conducted a cross-sectional study from January 2016 through September 2018 using data from nationwide registries from Austria/ Germany, Sweden and the US. In the DPV register, all IRBs at the participating institutions consented to the transfer of pseudonymized data to University of Ulm for joint analysis. The ethics committee of Ulm University approved joint data analysis for the DPV database (202/ 09). The ethics comittee at the University of Gothenburg and the IRB at Jaeb Center for Health Research also approved the study.

\section{Austrian/German Registry}

Diabetes Patient Follow-up (DPV) was established in 1995 [16]. Currently, participating centres in Austria and Germany prospectively document demographic and clinical data on adults and children with diabetes [16, 17]. Locally collected data are transferred twice annually to the University of Ulm, Germany, for central analysis and quality assurance. Data are collected from medical records, including patient history, for every visit. There are 106 participating centres in Germany and 5 in Austria for adults and 206 paediatric diabetes centres (including 18 centres in Austria). In DPV, a diagnosis of diabetes was established by specialized adult or paediatric diabetologists in concordance with current German and international guidelines, based on factors such as elevated fasting/postprandial/stimulated glucose together with presence of $\beta$-cell-antibodies, diabetic ketoacidosis at onset, ketonuria, insulin requirement and family history.

\section{Swedish Registry}

The Swedish National Diabetes Registry (NDR), established in 1996, includes adults with T1D [18]. In 2000, the Swedish diabetes register was expanded to include children in a paediatric registry for diabetes (Swediabkids). Collected data include diabetes history, management, monitoring, general health, lifestyle, medications, acute and chronic diabetic complications, other medical conditions and laboratory results. All diabetes outpatient clinics report to the NDR and $>95 \%$ of adult persons with T1D in Sweden are expected to be included in the NDR. In the current study adults with T1D were included using the clinical definition including clinician's diagnosis of T1D and attending a diabetes outpatient clinic $[18,19]$.

\section{US Registry}

The Type 1 Diabetes Exchange (T1DX) registry consisted of 81 paediatric and adult endocrinology practices in 35 states in the US [20]. Data collection began in August 2010 from questionnaires administered at enrolment and then once annually. Glycosylated haemoglobin (HbA1c) levels were obtained from medical records for up to the past 10 years. T1D diagnosis was classified as definite or probable based on available information from medical records.

Definite T1D required presence of one or more of the following: (1) age $<10$ years at diagnosis; (2) positive pancreatic autoantibodies at any time (GAD-65, IA-2, ICA or ZnT8) or positive anti-insulin autoantibody at diagnosis only (within 10 days of starting insulin) or (3) presence of $\geq 2$ of the following clinical indicators suggestive of T1D: (a) age at diagnosis $<40$ years; (b) non-obese at diagnosis according to body mass index $(<95$ th percentile paediatric and $<30 \mathrm{~kg} / \mathrm{m}^{2}$ adult); (c) diabetic ketoacidosis (DKA) at any time; (d) plasma C-peptide $<0.8 \mathrm{ng} / \mathrm{ml}$ (with blood glucose $>80 \mathrm{mg} / \mathrm{dl}$ if available) at any time or (e) family history of T1D in a first-degree relative (parent, sibling or child). Cases without complete medical records to make a 
determination of definite T1D were classified as probable T1D [20].

\section{Renal Complications}

In the DPV registry albuminuria was defined as persistent albuminuria of $30-299 \mathrm{mg} / 24 \mathrm{~h}$ and $\geq 300 \mathrm{mg} / 24 \mathrm{~h}$ in at least two out of three samples. In NDR microalbuminuria was defined as two positive tests from three samples taken within 1 year, with an albumin creatinine ratio (ACR) $3-30 \mathrm{mg} / \mathrm{mmol}$ or urinary albumin 20-200 $\mu \mathrm{g} / \mathrm{min}$ (20-300 mg/l). Macroalbuminuria was defined as ACR $>30 \mathrm{mg} / \mathrm{mmol}$ or urinary albumin $>200 \mu \mathrm{g} / \mathrm{min}(>300 \mathrm{mg} / \mathrm{l})$ [3].

In the T1DX clinic registry microalbuminuria was defined as two consecutive albumin/ creatinine ratios (ACRs) in the range of 30-300 $\mathrm{mcg} / \mathrm{mg}$ or two out of the past three measurements [21]. Albuminuria/macroalbuminuria was defined as two consecutive ACRs $>300$ $\mathrm{mcg} / \mathrm{mg}$ or two out of the past three. In the T1DX patients were excluded from analyses who had nephropathy due to a cause other than diabetes, renal failure (either receiving dialysis or kidney transplant) or an absent ACR determination within 2 years.

eGFR based on creatinine was calculated using the CKD-EPI equation [22]. Chronic kidney disease (CKD) was defined as follows: stage 1 eGFR $\geq 90 \mathrm{ml} / \mathrm{min}$, stage 2 eGFR $=60-89 \mathrm{ml} /$ min, stage $3 \mathrm{eGFR}=30-59 \mathrm{ml} / \mathrm{min}$, stage 4 eGFR $=15-29 \mathrm{ml} / \mathrm{min}$ and stage 5 eGFR $<15 \mathrm{ml} / \mathrm{min}$ [22].

Current clinical assessment of renal function and an albuminuria measurement within 2 years were collected from medical records. Most eligible albuminuria measurements were from spot collection [21].

Renal function was analyzed for the total cohort and by country and stratified by diabetes duration ( $<20$ years, $20-40$ years and $>40$ years).

\section{Risk Factors and Treatments}

We performed descriptive analyses of the following risk factors for renal complications in each diabetes register: age, sex, HbA1c, BMI, systolic and diastolic blood pressure, treatment with angiotensin-converting-enzyme-inhibitors (ACEi)/angiotensin II receptor blockers (ARB), diabetes duration, previous cardiovascular disease (CVD) stroke, heart failure, myocardial infarction, peripheral arterial disease, glucoselowering treatments and glucose monitoring systems (continuous glucose monitoring [CGM] or intermittently scanned CGM-isCGM).

HbA1c was reported both in $\mathrm{mmol} / \mathrm{mol}$ (IFCC units) and \% (NGSP units) according to guidelines [23].

\section{Statistical Analyses}

Continuous variables were reported as median (interquartile range) or mean \pm standard deviation (SD). Confidence interval was 95\%. Categorical variables were reported as frequency (percentage). Proportions of albuminuria for patients managed with MDI and insulin pumps were compaired with logistic regression. For data analysis we used MEANS and FREQ procedure for descriptive statistics from the SAS statistical software package version 9.4, build TS1M5, on a Windows Server 19 mainframe.

\section{RESULTS}

\section{Study Population}

We identified 78,926 adults with T1D. In Table 1 overall patient characteristics in the combined cohort from the three diabetes registers $(n=78,926)$ are shown. Mean age was 44.4 years and the mean diabetes duration 21.6 years. The numbers of patients from the different registers were 24,566 in the DPV, 45,105 in the NDR and 9255 in the T1DX.

\section{Risk Factors and Glucose-Lowering Treatments}

In Table 2 overall patient characteristics as well as risk factor control and glucose-lowering treatments in the different geographical regions are shown. HbA1c was higher in the DPV registry of $8.2 \%(66 \mathrm{mmol} / \mathrm{mol})$, followed by T1DX 
Table 1 Patient characteristics and renal complications in the combined cohort of the three included diabetes registries

\begin{tabular}{ll}
\hline Total cohort & 78,926 \\
Age, years & $44.4 \pm 18.4$ \\
Diabetes duration, years & $21.6 \pm 15.3$ \\
eGFR (CKD Epi), ml/min (mean) & $94.0 \pm 25.6$ \\
Microalbuminuria, \% & 13.0 \\
(95\% CI) & $12.7-13.3 \%$ \\
Macroalbuminuria, \% & 3.9 \\
(95\% CI) & $3.7-4.1 \%$ \\
Renal function & \\
eGFR $\geq 90 \mathrm{ml} / \mathrm{min}, \%$ & 62.1 \\
eGFR 60 to $<90 \mathrm{ml} / \mathrm{min}, \%$ & 27.9 \\
eGFR 45 to $<60 \mathrm{ml} / \mathrm{min}, \%$ & 4.9 \\
eGFR 30 to $<45 \mathrm{ml} / \mathrm{min}, \%$ & 2.7 \\
eGFR $<30 \mathrm{ml} / \mathrm{min}, \%$ & 2.3 \\
\hline
\end{tabular}

with $8.1 \%(65 \mathrm{mmol} / \mathrm{mol})$ and lowest in the NDR with $7.8 \%(62 \mathrm{mmol} / \mathrm{mol})$. Mean diabetes duration was shortest in the DPV with 16.4 years compared to 22.1 years and 24.3 years in the T1DX and NDR, respectively. Moreover, mean systolic blood pressure was higher in DPV registry with $130 \mathrm{mmHg}$ compared to $123.1 \mathrm{mmHg}$ and $127.0 \mathrm{mmHg}$ in T1DX and NDR, respectively.

Insulin pump use was most common in the T1DX (63.4\%) compared to $20.1 \%$ and $22.8 \%$ in DPV and NDR, respectively. There were large differences in use of CGM, from $58.3 \%$ in the NDR to $8.2 \%$ in DPV (Table 2).

There were discrepancies in previous cardiovascular disease between the registries, with lower prevalence in the NDR and T1DX (5.5\% and $7.5 \%$, respectively) and higher prevalence in the DPV (16.0\%).

\section{Renal Complications in the Total Cohort and by Geographic Region}

In the total cohort $13.0 \%$ (95\% CI $12.7-13.3 \%)$ developed microalbuminuria and 3.9\% (95\% CI $3.7-4.1 \%)$ developed macroalbuminuria (Table 1). The prevalence of microalbuminuria was higher in the DPV with $19.1 \%$ (95\% CI 17.9-19.5\%) compared to NDR $12.6 \%$ (95\% CI $12.3-12.9 \%)$ and T1DX $7.1 \% \quad(95 \% \quad \mathrm{CI}$ 6.5-7.7\%), respectively. In the T1DX, macroalbuminuria was less common with $1.2 \%$ (95\% CI $0.9-1.4 \%)$ compared to the prevalence in the NDR and DPV with 4.1\% (95\% CI 3.9-4.3\%) and $5.4 \%$ (95\% CI 4.9-5.7\%), respectively.

In the total cohort, mean eGFR was $94.0 \mathrm{ml} /$ min. Approximately $10 \%$ of patients had an eGFR $<60 \mathrm{ml} / \mathrm{min}$ (Table 1). More patients had an eGFR $<60 \mathrm{ml} / \mathrm{min}$ in the DPV than in the other two registers in all evaluated eGFR $<60 \mathrm{ml} / \mathrm{min}$ categories (Table 2). For eGFR $45-60 \mathrm{ml} / \mathrm{min}$ the prevalence ranged from $7.3 \%$ in the DPV to $4.2 \%$ in the NDR and for eGFR $30-45 \mathrm{ml} / \mathrm{min}$ it was $4.9 \%$ vs. $2.1 \%$ in the corresponding registers. There were $2.3 \%$ of patients in the total cohort with severe renal impairment (eGFR $<30 \mathrm{ml} / \mathrm{min}$ ) whereas $5.1 \%$ in the DPV belonged to this category.

\section{Renal Complications in Relation to Diabetes Duration}

The number and proportion of participants with micro- and macroalbuminuria in the total cohort stratified by diabetes duration are shown in Fig. 1. The prevalence of both micro- and macroalbuminuria increased consistently with longer diabetes duration. For patients with diabetes duration $<20$ years, $\quad 8.1 \% \quad(95 \% \quad$ CI 6.7-8.3\%) had microalbuminuria, which increased to $24.7 \%$ (95\% CI 23.7-25.5\%) at > 40-year diabetes duration. Corresponding estimates for macroalbuminuria were $1.7 \%$ (95\% CI $1.5-1.8 \%)$ and $8.3 \%$ (95\% CI $7.7-8.9 \%)$, respectively. In Fig. 2a, the prevalence of microand macroalbuminuria is shown as a function of diabetes duration as a continuous variable.

For renal function based on eGFR, a somewhat different pattern was seen compared with 
Table 2 Risk factors of renal complications and glucose-lowering treatments in the Austria/Germany, Swedish and US registries

\begin{tabular}{|c|c|c|c|}
\hline & $\begin{array}{l}\text { Austria/Germany (DPV), } \\
N=24,566\end{array}$ & $\begin{array}{l}\text { Sweden (NDR), } \\
N=45,105\end{array}$ & $\begin{array}{l}\text { US (T1DX), } \\
N=9255\end{array}$ \\
\hline Age, years & $42.0 \pm 20.1$ & $47.0 \pm 17.3$ & $38.6 \pm 17.9$ \\
\hline Sex $\%$ male & 53.0 & 55.6 & 47.2 \\
\hline Diabetes duration, years & $16.4 \pm 14.0$ & $24.3 \pm 15.6$ & $22.1 \pm 13.7$ \\
\hline \multirow[t]{2}{*}{$\mathrm{HbAlc}(\%$ and $\mathrm{mmol} / \mathrm{mol})$} & $8.2 \pm 2.0$ & $7.108 \pm 1.2$ & $8.1 \pm 1.6$ \\
\hline & $66 \pm 10.1$ & $62 \pm 7.25$ & $65 \pm 9.6$ \\
\hline On insulin pump, \% & 20.1 & 22.8 & 63.4 \\
\hline On CGM/isCGM, \% & 8.4 & 57.3 & 30.7 \\
\hline Systolic blood pressure, & $129.6 \pm 16.9$ & $127.0 \pm 14.5$ & $123.1 \pm 14.3$ \\
\hline $\mathrm{mmHg}$ & 38.12 & 29.78 & 16.09 \\
\hline \multicolumn{4}{|l|}{ ACEi/ARB use (mean) } \\
\hline Previous CVD, \% & 16.0 & 5.5 & 7.5 \\
\hline Microalbuminuria, \% & 19.1 & 12.6 & 7.1 \\
\hline (95\% CI) & $17.9-19.5 \%$ & $12.3-12.9 \%$ & $6.5-7.7 \%$ \\
\hline Macroalbuminuria, \% & 5.4 & 4.1 & 1.2 \\
\hline$(95 \% \mathrm{CI})$ & $4.9-5.7 \%$ & $3.9-4.3 \%$ & $0.9-1.4 \%$ \\
\hline \multicolumn{4}{|l|}{ Renal function } \\
\hline eGFR (CKD-EPI), $\mathrm{ml} / \mathrm{min}$ & $90.5 \pm 31.2$ & $95.1 \pm 23.3$ & $94.2 \pm 26.0$ \\
\hline $\begin{array}{l}\text { eGFR } 60 \text { to }<90 \mathrm{ml} / \mathrm{min} \text {, } \\
\%\end{array}$ & 25.9 & 28.1 & 30.4 \\
\hline $\begin{array}{l}\text { eGFR } 45 \text { to }<60 \mathrm{ml} / \mathrm{min} \text {, } \\
\%\end{array}$ & 7.3 & 4.2 & 5.1 \\
\hline $\begin{array}{l}\text { eGFR } 30 \text { to }<45 \mathrm{ml} / \mathrm{min} \text {, } \\
\%\end{array}$ & 4.9 & 2.1 & 2.6 \\
\hline $\mathrm{eGFR}<30 \mathrm{ml} / \mathrm{min}, \%$ & 5.1 & 1.5 & 2.1 \\
\hline
\end{tabular}

micro- and macroalbuminuria in relation to diabetes duration. In correspondence with analyses of micro- and macroalbuminuria, impaired renal function was most common in persons with the longest diabetes duration ( $>40$ years). However, persons with diabetes duration 20-40 years showed generally less reduced eGFR compared with patients with $<20$ years diabetes duration (Fig. 1b).

\section{Renal Complications and Insulin Delivery Method}

In patients managed with MDI $14.4 \%$ had microalbuminuria compaired with $9.3 \%$ for those managed with insulin pump $(p<0.001)$. Macroalbuminuria was also more common in those with MDI $4.4 \%$ vs. $2.6 \%$ ( $p<0.001)$. The diabetes duration was 21 years in MDI users and 


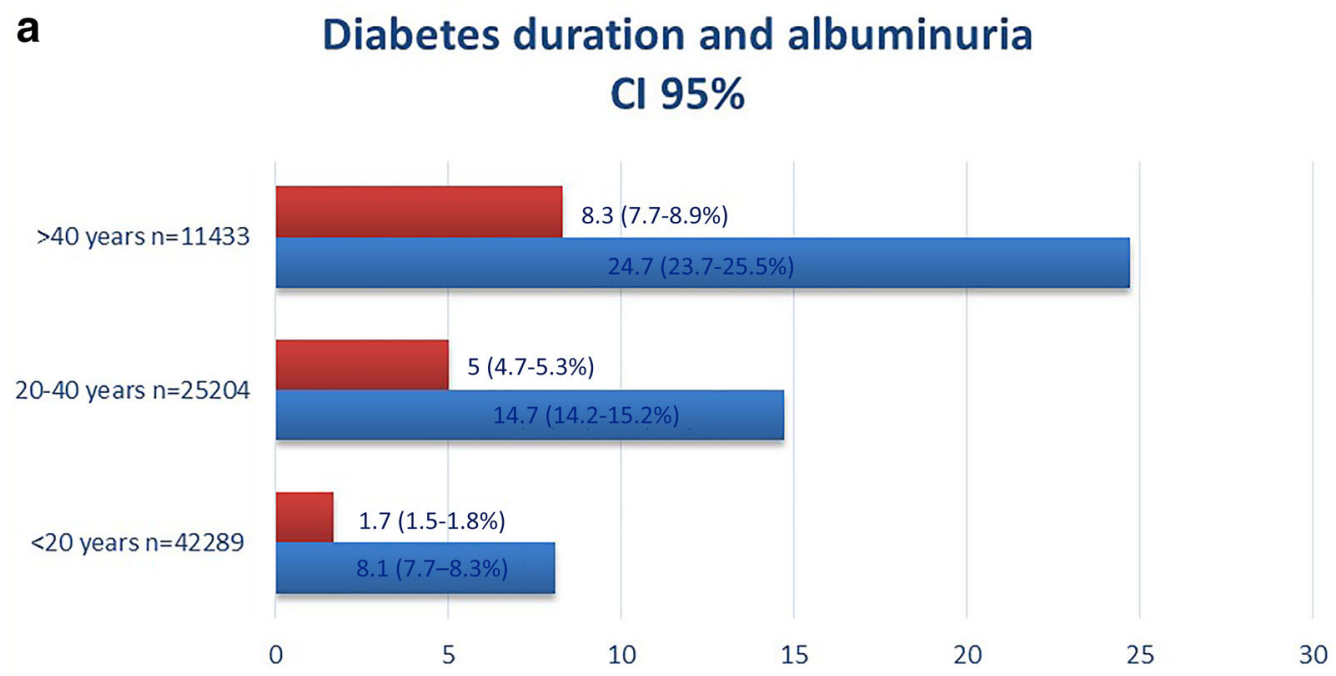

\section{b Diabetes duration and renal function}

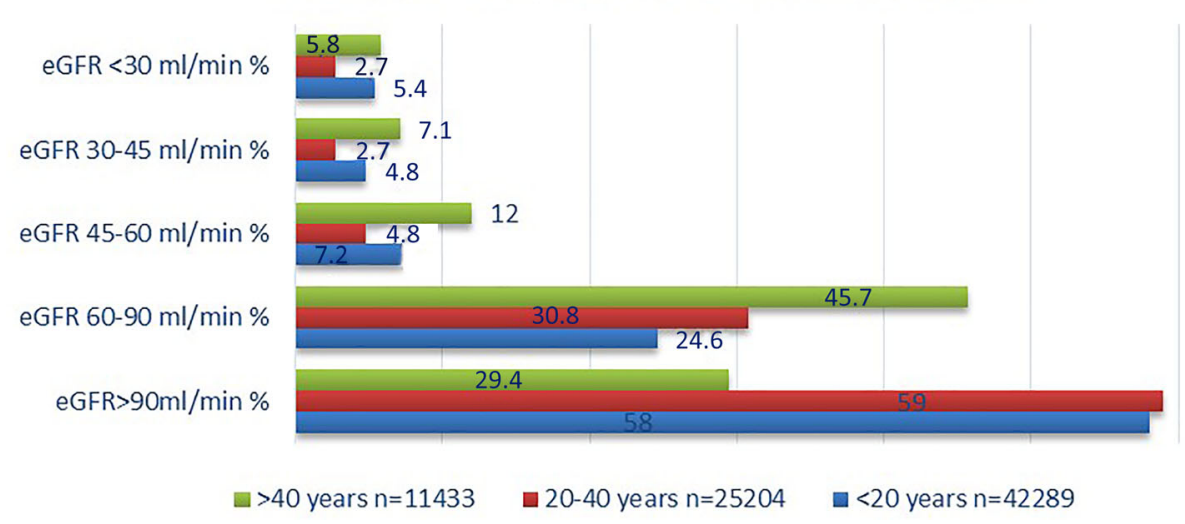

Fig. 1 a, b Microalbuminuria (blue bar), macroalbuminuria (red bar) and renal function for persons with diabetes duration $<20$ years, $20-40$ years and $>40$ years evaluated in the combined cohort of the three registers

23 years in pump users. When adjusting for diabetes duration both microalbuminuria $(p<0.001)$ and macroalbuminuria $(p<0.001)$ were still significantly more common in patients with MDI.

\section{DISCUSSION}

\section{Principal Findings}

This cohort study using data from national registries in Austria/Germany, Sweden and the US including 78,926 persons with T1D shows that renal complications are still common in persons with T1D. Also, in patients with relatively short diabetes duration $(<20$ years), generally having experienced modern diabetes care since diagnosis, $8 \%$ of patients had already developed microalbuminuria. Overall in the total cohort, $4 \%$ had macroalbuminuria and $10 \%$ a clearly reduced renal function (eGFR $<60 \mathrm{ml} / \mathrm{min}$ ). Approximately 1 out of 40 patients had severely impaired renal function (eGFR $<30 \mathrm{ml} / \mathrm{min}$ ). The risk of renal complications increased with longer diabetes duration, and one in four patients with diabetes duration $>40$ years had developed microalbuminuria. 


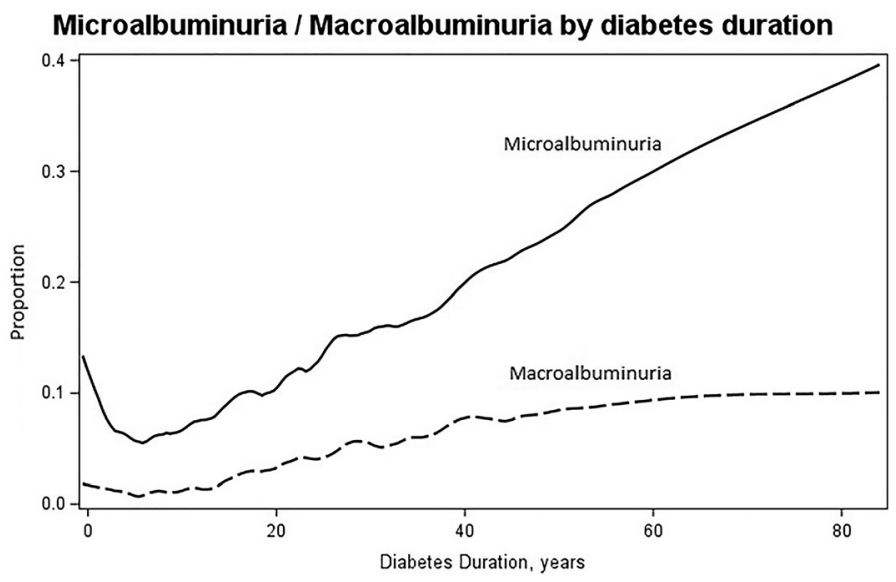

Fig. 2 Prevalence of microalbuminuria and macroalbuminuria in relation to diabetes duration as a continuous variable in the combined cohort consisting of patients from Austria, Germany, Sweden and the US

\section{Earlier Studies}

Microalbuminuria as an early complication of T1D, with onset in the first 5 years after diabetes diagnosis, has been described in large observational studies. The prevalence of microalbuminuria $(20-200 \mu \mathrm{g} / \mathrm{min})$ measured from $24-\mathrm{h}$ urine collection in the EURODIAB IDDM Complications Study was $18 \%$ [15].

The Diabetes Control and Complications Trial (DCCT) showed that intensive treatment reduced incident microalbuminuria $($ AER $>40 \mathrm{mg} / 24 \mathrm{~h})$ by $39 \%$ and incident macroalbuminuria (AER $>300 \mathrm{mg} / 24 \mathrm{~h}$ ) by $54 \%$ [2, 24]. The Epidemiology of Diabetes Interventions and Complications (EDIC) follow-up study demonstrated that after 17-18 years of follow-up, the prevalence of microalbuminuria was $18.4 \%$ with intensive treatment during the DCCT, compared with $24.9 \%$ with conventional treatment. These findings demonstrate that intensive diabetes treatment yields durable renal benefits over long time periods [24]. The prevalence of microalbuminuria of $18-24 \%$ in the Eurodiab and EDIC studies can be related to the prevalence of $13 \%$ in the current cohort where the mean diabetes duration was 22 years. Despite all the progress made in the treatment of diabetes from these studies, a significant number of people with T1D still do not achieve glycaemic targets and are inadequately treated for hypertension and dyslipidaemia [25].

\section{Explanations and Interpretations}

Hyperglycaemia is a major risk factor for the development of renal complications [2, 3, 26]. Our finding that microalbuminuria is relatively common in patients with diabetes duration $<20$ years is probably due to the fact that many patients had high glucose levels over longer time periods despite treatment with MDI or pump therapy. Furthermore, the current study also shows that although treatments have improved, mean HbA1c levels were clearly above target with country average ranging from 7.8 to $8.2 \%(62-66 \mathrm{mmol} / \mathrm{mol})$ in the different geographical regions studied.

DKD has a multifactorial pathogenesis due to microenvironmental changes in the diabetic kidney. Pathological glomerular changes are one of the most important signs of DKD that appear in many cases within 0-3 years after diabetes diagnosis [27]. Changes such as thickening of the glomerular basement membrane (GBM), podocyte injury, mesangial matrix expansion and loss of glomerular endothelium fenestrations damage the glomerular filtration barrier and microvascular permeability and are clinically expressed as micro- and macroalbuminuria [28]. Other changes due to hyperglycaemia are mesangial cell proliferation and 
glomerulosclerosis. Typically, hyperglycaemia may lead to increased non-enzymatic glycosylation of proteins in the mesangial matrix and to the most distinctive lesions of DKD, called Kimmelstiel-Wilson (K-W) nodules [28]. Current studies support tubulointerstitial changes as the first stage of DKD or at least an accompanying sign of glomerular changes [29].

Microalbuminuria was more common in the Austrian/German register compared with the Swedish and US registers and more patients had impaired renal function in all categories of eGFR $<60 \mathrm{ml} / \mathrm{min}$. This is likely not explained by diabetes duration, being essential for development of microvascular complications [11], since diabetes duration was on average shorter in the Austrian/German register of 16 years than in the Swedish and US registries of 22-24 years. Since hyperglycaemia is a prerequisite for development of early signs of diabetic nephropathy, it is possible that patients in the DPV register have had higher historical glucose levels. The mean HbA1c levels over the evaluated time period (years 2015-2017) was also higher with $8.2 \%$ than in the Swedish registry with $7.8 \%$ and the US with $8.1 \%$. It is also possible that HbA1c levels may have differed further back in the patient's history. Blood pressure was also higher in the DPV register with mean systolic blood pressure of $130 \mathrm{mmHg}$ compared with $127 \mathrm{mmHg}$ and $123 \mathrm{mmHg}$ in the Swedish and US registers, respectively. Moreover, differences in comprehensiveness of the populations included in the registries and different treatment strategies may have contributed to some extent.

\section{Implications}

More focused treatments for renal complications are needed to an even greater extent since many T1D patients continue to develop renal complications. Early signs of renal complications are associated with not only future renal progression but also greater risk for myocardial infarction, heart failure, amputations and shorter life expectancy [5-8, 30]. Improving glycaemic control is critical to preventing renal complications; thus, glycaemic control strategies need to be focused, including CGM for MDI treated patients and in conjunction with insulin pumps $[13,14,31]$. In addition to reducing $\mathrm{HbA1c}$, less glycaemic variability, less time in hypoglycaemia and less time in very high glucose levels may be important [2, 3, 32].

In the current study, patients with insulin pumps had fewer renal complications also after adjusting for diabetes duration. Since in this study[3] did not have the full historical HbA1c curve, it should be interpreted with caution when it comes to possible causality. It is possible that insulin pump users had better HbA1c already before receiving insulin pumps. However, in an earlier observational study in Sweden at ten hospitals it was found that those with high HbA1c values received insulin pumps to a greater extent, contradicting this assumption [33]. It is possible that insulin pumps provide overall better glucose-reducing effects but also less glycaemic variability and may explain the lower risk of renal complications [2, 3, 32].

Blood pressure also needs to be well regulated, including use of renin angiotensin-aldosterone system (RAAS) inhibitors when complications appear [34, 35]. Recently, SGLT2 -inhibitors have shown promising results in preventing renal complications in large randomized trials of patients with T2D [36]. Indications also exist in T1D patients; these agents might have specific renal protective effects in addition to the HbA1c-lowering effect. One SGLT-2 inhibitor is already approved in Europe for patients with T1D who have failed to achieve desired glycaemic control despite optimal insulin therapy. However, the increased risk of diabetic ketoacidosis in patients with T1D warrants caution in this population [37] and their use is restricted to well-instructed and compliant patients meeting certain conditions (a complement to insulin in patients with $\mathrm{BMI} \geq 27 \mathrm{~kg} / \mathrm{m}^{2}$ ).

Future works aim to describe the diabetes care in different populations, in line with the current need to focus on the prevalence of renal complications and not only on risk factors (e.g. HbA1c, blood pressure, lipids, smoking). The magnitude of renal complications in a population gives an indication of future overall risks 
for diabetes complications, but also the overall historical risk factor control.

\section{Strengths and Limitations}

One strength of the current study includes use of a large sample of individuals with T1D with a wide distribution of socioeconomic factors in Europe and North America. Additionally, the NDR has nationwide coverage.

Since data in the T1DX and DPV registries were collected from diabetes centres (i.e. not population-based), they may not be fully representative of the general diabetes care. The total adult numbers of people with T1D in Germany and Austria are together approximately 400,000 and in the US estimated to be 1.4-1.5 million individuals [38-40]. Potential differences in data ascertainment are also possible. Moreover, criteria for defining albuminuria differed to some extent among registries, but despite these differences the incidence of albuminuria in the three registers was similar. In two of the registries other causes of proteinuria than DKD were not excluded. However, the use of multiple registries confirms across nations that preventive treatments are today still insufficient in T1D regarding renal complications.

\section{CONCLUSIONS}

In this analysis using nationwide registries including patients in routine clinical practice a substantial proportion of persons with T1D had renal complications after $<20$ years after diagnosis. Improvements in early diagnosis and diabetes care are urgently needed to prevent renal complications and reduce risk of cardiovascular disease and mortality. Efficient glucoselowering treatments in combination with renal protective therapies focusing on control of blood pressure, lipid levels and cessation of smoking are also needed to prevent overt DKD and progression to end-stage renal disease.

\section{ACKNOWLEDGEMENTS}

We sincerely thank all clinicians and staff working with collecting data from the included registers making the current evaluations possible.

Funding. Analyses from the Swedish registry were funded by the Swedish state (ALF grant) and the NovoNordisk Foundation. The DPV registry is funded by the German Center for Diabetes Research (DZD, grant no. 82DZD14A02) and the German Robert Koch Institute (RKI). The journal's Rapid Service fee was funded by NU Hospital Group.

Authorship. All named authors meet the International Committee of Medical Journal Editors (ICMJE) criteria for authorship for this article, take responsibility for the integrity of the work as a whole, and have given their approval for this version to be published.

Author Contributions. MD and ML wrote a first draft. JG did the statistical analyses. All authors participated in concept and design of the study and interpretation of data and critically reviewed the manuscript.

Prior Presentation. This study has earlier been presented at the European Association for the Study of Diabetes (EASD) Congress 2019.

Disclosures. Mary Dena, Ann-Marie-Svensson, Katarina Eeg Olofsson, Laura Young, Anders Carlson, Kellee Miller, Julia Grimsmann, Reinhard Welp, Julia K. Mader, David M Maahs, Reinhard W. Holl and Marcus Lind have nothing to disclose.

Compliance with Ethics Guidelines. In the DPV register, all IRBs at the participating institutions consented to the transfer of pseudonymized data to University of Ulm for joint analysis. The ethics committee of Ulm University approved joint data analysis for the DPV database (202/09). The ethics committee at the University of Gothenburg and the IRB at Jaeb Center for Health Research also approved the study. 
Data Availability. The datasets generated during and/or analyzed during the current study are available in the T1D Exchange repository, https://public.jaeb.org/dataset/536. The datasets based on the Austria/German registry (DPV-register) generated during and/or analyzed during the current study are not publicly available as sharing patient-level data is not covered by the patient consent provided. The datasets from the Swedish National Diabetes Register are not publicly available, but can be retrieved on reasonable request in collaboration with the responsible researchers.

Open Access. This article is licensed under a Creative Commons Attribution-NonCommercial 4.0 International License, which permits any non-commercial use, sharing, adaptation, distribution and reproduction in any medium or format, as long as you give appropriate credit to the original author(s) and the source, provide a link to the Creative Commons licence, and indicate if changes were made. The images or other third party material in this article are included in the article's Creative Commons licence, unless indicated otherwise in a credit line to the material. If material is not included in the article's Creative Commons licence and your intended use is not permitted by statutory regulation or exceeds the permitted use, you will need to obtain permission directly from the copyright holder. To view a copy of this licence, visit http://creativecommons.org/licenses/bync/4.0/.

\section{REFERENCES}

1. nFacts F, Diabetes ON. Centers Dis Control Prev US Dep Heal Hum Serv 2011. National Diabetes Fact Sheet. Centers for Disease Control and Prevention. "National diabetes fact sheet: national estimates and general information on diabetes and prediabetes in the United States". Atlanta: US Department of Health and Human Services, Centers for Disease Con, 2011.

2. Diabetes Control and Complications Trial Research Group. The effect of intensive treatment of diabetes on the development and progression of long-term complications in insulin-dependent diabetes mellitus. Engl J Med. 1993;329:977-86.

3. Lind M, Pivodic A, Svensson A-M, Ólafsdóttir AF, Wedel $\mathrm{H}$, Ludvigsson J. HbA1c as a risk factor for retinopathy and nephropathy in persons with type 1 diabetes: Swedish Cohort study. BMJ. 2019;28: 366-71.

4. Schwandt A, Bergis D, Denkinger M, Gollisch K, Sandig D, Stingl H, Zimny S, Holl RW. Risk factors for decline in renal function among young adults with type 1 diabetes: analysis of real-life data from the German/Austrian DPV registry. J Diabetes Complicat. 2018;32(10):940-6.

5. Hallström S, Pivodic A, Rosengren A, Ólafsdóttir AF, Svensson A-M, Lind M. Risk factors for atrial fibrillation in persons with type 1 diabetes, an observational cohort study of 36258 patients from the Swedish National Diabetes Register. Diabetes Care. 2019;42(8):1530-8.

6. Matuleviciene-Anägen V, Rosengren A, Svensson AM, Pivodic A, Gudbjörnsdottir S, Wedel H, Kosiborod M, Haraldsson B, Lind M. Glycaemic control and excess risk of major coronary events in persons with type 1 diabetes. Heart. 2017;103(21):1687-95. https://doi.org/10.1136/heartjnl-2016-311050.

7. Vestberg D, Rosengren A, Olsson M, Gudbjörnsdottir S, Haraldsson B, Svensson AM, Lind M. Decreased eGFR as a risk factor for heart failure in 13781 individuals with type 1 diabetes. J Diabetes Sci Technol. 2016;10(1):131-6.

8. Lind M, Svensson AM, Kosiborod M, Gudbjörnsdottir S, Pivodic A, Wedel H, Dahlqvist S, Clements $\mathrm{M}$, Rosengren A. Glycemic control and excess mortality in type 1 diabetes. $\mathrm{N}$ Engl J Med. 2014;371(21):1972-82.

9. Alicic RA, Rooney MT, Tuttle KR. Diabetic kidney disease: challenges, progress and possibilities. CJASN. 2017;12(12):2032-45.

10. The Swedish National Diabetes Register (NDR), Annual Report 2018. http://www.ndr.nu. Accessed 1 Sept 2021.

11. The Diabetes Control and Complications Trial Research Group. The relationship of glycemic exposure (HbA1c) to the risk of development and progression of retinopathy in the diabetes control and complications trial. Diabetes. 1995;44:968-83.

12. Sohaib VA, Kim DC, Yoon $\mathrm{CH}$, Benitez-Aguirre $\mathrm{P}$, Hing S, Ptyke A, Chan A, Craig MA. Association between $\mathrm{HbA}_{1 \mathrm{c}}$ variability and risk of microvascular complications in adolescents with type 1 diabetes. JCEM. 2016;9(101):3257-63. 
13. Lind M, Polonsky W, Hirsch I, et al. Continuous glucose monitoring vs conventional therapy for glycemic control in adults with type 1 diabetes treated with multiple daily insulin injections. The GOLD randomized clinical trial. JAMA. 2017;317(4):379-87. https://doi.org/10.1001/jama. 2016.19976.

14. Battelino T, Conget I, Olsen B, et al. SWITCH Study Group. The use and efficacy of continuous glucose monitoring in type 1 diabetes treated with insulin pump therapy. Diabetologia. 2012;55(12):3155-62.

15. EURODIAB ACE Study Group. Variation and trends in incidence of childhood diabetes in Europe. Lancet. 2000;355:873-6.

16. van Mark G, Lanzinger S, Barion R, Degenhardt M, Badis S, Noll H, Bramlage P, Seufert J, Holl RW. Patient and disease characteristics of adult patients with type 1 diabetes in Germany: an analysis of the DPV and DIVE database. Therap Adv Endocrinol Metab. 2019;10:2042018819830867.

17. Weinstock RS, Schutz-Fuhrmann I, Connor CG, Hermann JM, Maahs DM, Schutt M, Agarwal S, Hofer SE, Beck RW, Holl R. for the T1D Exchange Clinic Network and the DPV Initiative "Type 1 diabetes in older adults: comparing treatments and chronic complications in the United States T1D Exchange and the German/Austrian DPV registries. " Diabetes Res Clin Pract. 2016;122:28-37.

18. Gudbjörnsdottir S, Svensson AM. NDR report 2017. Swedish Diabetes Registry.

19. Eeg-Olofsson K, Cederholm J, Nilsson PM, Zetheluis B, Svensson A-M, Gudbjörnsdottir S, Eliasson B. Glycemic control and cardiovascular disease in 7,454 patients with type 1 diabetes. Diabetes Care. 2010;33:1640-6.

20. Beck RW, Tamborlane WV, Bergenstal RM, et al. The T1D exchange clinic registry. J Clin Endocrinol Metab. 2012;97:4383-9.

21. Mark D, DuBose SN, Maahs DM, Beck RW, Fox LA, Gubitosi-Klug R, Laffel LM, Miller KM, Speer H, Tamborlane WT, Tansey MJ. Factors associated with microalbuminuria in 7549 children and adolescents with type 1 diabetes in the T1D exchange clinic registry. Diabetes Care. 2013;36:2639-45.

22. Levey AS, Stevens LA. Estimating GFR using the CKD Epidemiology Collaboration (CKD-EPI) creatinine equation: more accurate GFR estimates, lower CKD prevalence estimates, and better risk predictions. Am J Kidney Dis. 2010;55(4):622-7.

23. Hanås R, John G, International HbA1c Consensus Committee. Consensus statement on the worldwide standardization of the hemoglobin A1C measurement. Diabetes Care. 2010;2010(33): 1903-4. https://doi.org/10.2337/dc10-0953.

24. DCCT/EDIC Research Group. Sustained effect of intensive treatment of type 1 diabetes mellitus on development and progression of diabetic nephrophaty: the Epidemiology of Diabetes Interventions and Complications (EDIC) study. JAMA. 2003;30: 2159-67.

25. Viral NS, Grimsmann JS, Foster N, Dost A, Miller K, Pavel M, Weinstock RS, Karges W, Maahs DM, Holl RW. Undertreatment of cardiovascular risk factors in the type 1 diabetes exchange clinic network (USA) and the prospective diabetes follow-up (Germany/Austria) registries. Diabetes Obes Metab. 2020;22:1577-85.

26. Reidy K, Kand HM, Hostetter T, Susztak K. Molecular mechanism of diabetic kidney disease. J Clin Investig. 2014;124:2333-40.

27. KDOQI. KDOQI clinical practice guidelines and clinical practice recommendations for diabetes and chronic kidney disease. Am J Kidney Dis. 2007;49(2 Suppl 2):S12-154.

28. Kimmelstiel P, Wilson C. Intercapillary lesions in the glomeruli of the kidney. Am J Pathol. 1936;12(1):83-98.

29. Gilbert RE. Proximal tubulopathy: prime mover and key to therapeutic target in diabetic kidney disease. Diabetes. 2017;66:791-800.

30. Olfsdottir AF, Svensson AM, Pivodic A, Gudbjornsdottir S, Nyström T, Wedel H, Rosengren A, Lind M. Excess risk of lower extremity amputations in people with type 1 diabetes compared with the general population: amputations and type 1 diabetes. BMJ. 2019;7(1): e000602. https://doi.org/10.1136/ bmjdrc-2018-000602.

31. Brown SA, Kovatchev BP, Raghinaru D, Lum JW, et al. Six-month randomized multicenter trial on close-loop control in type 1 diabetes. NEJM. 2019;381:1707-17. https://doi.org/10.1056/ NEJMoa1907863.

32. Hirsch IB. Glycemic variability and diabetes complications: does it matter? Of course it does! Diabetes Care. 2015;38(8):1610-4.

33. Carlsson B-M, Nord Andersson P, Almervik J, Carstensen J, Lind M. Availability of insulin pump therapy in clinical practice. Diabet Med. 2012;29(8):1055-9.

34. Remuzzi G, Ruggenenti P, Perna A, Dimitrov BD, de Zeeuw D, Hille DA, Shahinfar S, Carides GW, Brenner BM, for the RENAAL Study Group. Continuum of renoprotection with losartan at all stages 
of type 2 diabetic nephropathy: a post hoc analysis of the renaal trial results. JASN. 2004;15(12): 3117-25.

35. Roscino SS, Lambers Heerspink HJ, de Zeeuw D. The effect of RAAS blockade on the progression of diabetic nephropathy. Nat Rev Nephrol. 2014;10: 77-87.

36. Thomson SC, Vallon V. Renal effects of sodiumglucose co-transporter inhibitors. Am J Med. 2019;132:S30-8.

37. Ogawa W, Sakaguchi K. Euglycemic diabetic ketoacidosis induced by SGTL2 inhibitors: possible mechanism and contributing factors. J Diabetes Investig. 2015. https://doi.org/10.1111/jdi.12401.
38. Robert Koch Institut https://www.rki.de/EN/ Content/Health_Monitoring/Main_Topics/ Chronic_Disease/Diabetes/diabetes_node. html;jsessionid= F9A2DB5AC7E24137BF77C22FE6FCB905. internet061. Accessed 27 Sep 2021.

39. Face Diabetes. https://www.facediabetes.at/zahlenund-fakten.html\#: :text=30.000\%20Menschen $\%$ 20in\%20\%C3\%96sterreich\%20leiden, davon\% 20sind\%20etwa\%201600\%20Schulkinder. Accessed 27 Sep 2021.

40. ADA Statistics. https://www.diabetes.org/resources/ statistics/statistics-about-diabetes. Accessed 27 Sep 2021. 